\title{
Book Review: The Emergent Knowledge Society and the Future of Higher Education: Asian Perspectives
}

\author{
Edited by Deane E. Neubauer. \\ New York: Routledge, 2012. 240 pp. \\ ISBN: 978-0-415-60869-5.
}

\begin{abstract}
We all experience the remarkable speed at which society is changing. We are living in exponential times. Information and its effects are at the core of major transformations. Globalization and technology help us access what a generation ago we would not even have dreamt of. What are the impacts of these substantial changes and resulting paradigm shifts? How do they affect higher education? Throughout The Emergent Knowledge Society and the Future of Higher Education: Asian Perspectives, Deane E. Neubauer and a diverse group of contributors attempt to map how this almost chaotic and increasing flux of information is influencing higher education in Asia. It is assumed as a central thesis that society and all its institutions are transformed and reshaped by an unstoppable cycle of information referred to as the "global knowledge society."
\end{abstract}

Using different case studies and broad analyses, the book does not follow a clear section pattern, but rather an interesting mix of national and transnational descriptions of trends. Chapter 1, therefore, orients the reader to the major problems universities in East Asia face in their quest to handle and produce knowledge in a competitive market. Universities are trying to catch up with what is considered an unavoidable agenda-becoming a top research university with a distinct identity. This is especially relevant when the increasing competition for funds and preeminence is blurring differences between academia and business. Chapter 2 discusses how to connect the wealth of information with innovation. Peter Hershock goes through many significant complexities that interact and make knowledge possible. In doing so, he recognizes that purposive wisdom needs to screen and utilize knowledge. Producing information in itself does not lead to solutions, an obvious statement that seems not to be so clear when universities pursue quality and innovation. Chapters 3 through 7 attempt to deal with the over imposing research university model and several other important dimensions of higher education. Is the research university model the best fit for the emergent knowledge economies? If so, how should a university design its curriculum and activities to propel a stronger correlation between knowledge and wealth? Chapters 5 and 6 grapple with these tough questions using the cases of Malaysia and Taiwan. In addition, Chapter 7 asks what the role of universities in the knowledge society is. Evidently, Asian universities are going through a transformation as they redefine their roles and purposes, as Charas Suwanwela asserts, "The traditional roles of universities must undergo paradigm changes to meet the new demands and opportunities created by the knowledge society . . . and universities have many important roles in building national competitiveness” (97). Following the same line of thinking, Chapter 8 discusses some of the challenges students face in producing knowledge. Using the Japanese perspective as a reference, Akira Arimoto challenges the lack of coordination between undergraduate and graduate studies and students. Teaching is frequently neglected and undergraduate students are left behind without the proper coaching to produce ideas; this is what the author calls "the opposite direction to the Humboldtian ideal" (114) that promotes the integration of teaching and research as a unique advantage of modern universities. Chapters 9 through 11 turn to quality as a central problem, offering national examples from Malaysia, South Korea, Singapore, and Hong Kong. If universities want to compete globally, is there any quality pattern or system that assures they are doing well? This leads to questions of accreditation, the discussion of which the various authors complicate by looking at the tensions that exist between the different paradigms state and private accrediting bodies operate under in order to ensure quality. Chapter 12 then turns to a very often-disregarded matter, namely the need to orient and counsel students to develop a broader understanding of reality. According to Rose Marie SalazarClemeña, this is a natural result of over-emphasizing the research dimension as a panacea for all problems. "[P]rioritize[ing] research over the two other missions of the university-teaching and community service" she contends, "[moves] teaching and learning from the center to the fringes of academic life” (162). Meeting the needs of the labor market is not the only mission for 
universities, although most policies seem to go that direction. Chapter 13 approaches the gender imbalance universities need to address. If higher education wants to become a prominent force that drives knowledge and innovation, it must be, Karuna Chanana argues, more inclusive to minorities and women. A university that looks to interact with a knowledge society ought to embrace all its actors. Finally, in the last two chapters, Neubauer tackles one of the underlining concerns at the core of the contemporaneous higher education: alignment. This issue strikes the difficulties in defining what a university is and what it should be doing to embrace change and the needs of academia and society. One of the main theses is that universities increasingly are engaging in activities that resemble business and market practices, thus "misaligning" institutions to what they should be doing. Although Neubauer does not clearly state what a university should do, he raises critical questions to ponder options. Higher education is undergoing a profound transition and if it does not change, it will become obsolete over time, warns the writer.

Generally speaking, this piece of scholarly work points to important issues that are very much necessary for rethinking the purpose(s) of higher education. However, one may wonder whether policymakers have any alternative given the social and political frameworks surrounding higher education. According to Sheila Slaughter and Gary Rhoades (2004), capitalism and neoliberalism are taking over and controlling any alternative model. Yes, it is possible to think and create substitute models. But they must be carefully crafted to avoid seclusion or, even worse, irrelevance. The idea of creating knowledge as the solution for most societal problems has become almost a religious belief that no one would dare to challenge. This is a sort of monopolistic theme that is stealing academia's soul and reshaping it in multiple ways (Albert 2003; Bok 2003). Who is taking the baton to train the person as a whole and not only his or her possibilities to be economic productive? What happened to the great ideal of wellrounded human beings such as Bildung? All of these issues seem to be pushed aside in the fight for high rankings and external funding. These are side effects no one wants, but many use to compete within this global race.

Since East Asian universities are in the making, they have a unique opportunity to create their own idea of higher education and offer something new and relevant to the twenty-first century. If it is true that higher education is reconfigured with and through knowledge, innovation should be the defining characteristic for Asian universities. Reproducing what western institutions have developed might be attractive, but not necessarily a good fit for this growing part of the world. Like everything else, society has a wide spectrum of needs, and the research elite university is not the single answer for all the challenges Asia confronts. In the concluding chapters, Neubauer seems to recognize that Asian societies would not benefit from reductionist models that skip valuable alternatives in the pursuit of reputation. Mass education poses challenges to many research oriented institutions. A range of professional schools that would supply the demand for professional and vocational training must also be addressed in Asia. The challenge, however, is to have a system that would provide this type of education within a clearly defined quality framework since elite institutions are too expensive and will not be able to absorb all the demand. Each country, if using all its human capacity, needs to offer a range of choices for the emergent knowledge society. One size fits all is not the best option for Asia (Spanier 2010).

Finally, it seems that an extensive production of knowledge without any well-defined boundaries has put society and therefore higher education in the middle of a vast ocean without borders. What is good today quickly becomes obsolete tomorrow. With the arrival of postmodern thinking, humans have erased many of the myths and traditional parameters for societies. On the other hand, individuals and social organizations assume that information will guide them. This proves to be astonishingly difficult given the ever-changing condition of information. What then is the task? Setting up clear benchmarks is probably one of the most relevant challenges policymakers from this whole region face. Answering these and similar questions will certainly be critical for the future and development of Asian societies.

Reviewed by Gustavo Gregorutti University of Montemorelos, Mexico

\section{References}

Albert, Mathieu. 2003. "Universities and the Market Economy: The Differential Impact on Knowledge Production in Sociology and Economics.” Higher Education 45 (2): 147182.

Bok, Derek. 2003. Universities in the Marketplace: The Commercialization of Higher Education. Princeton, NJ: University Press.

Slaughter, Sheila, and Gary Rhoades. 2004. Academic Capitalism and the New Economy: Markets, States, and Higher Education. Baltimore, MD: John Hopkins University Press.

Spanier, Graham B. 2010. "Creating Adaptable Universities.” Innovative Higher Education 35 (2): 91-99. 